\title{
Antibiotic resistance, virulence factors and genotyping of Uropathogenic Escherichia coli strains
}

\author{
Maryam Raeispour and Reza Ranjbar
}

\begin{abstract}
Background: The way of treating different types of infectious diseases is really important. Using genotyping method, we can determine the genetic relatedness between the organisms with different resistance profile from different sources. The aim of this study was to determine antibiotic resistance and genotyping of uropathogenic Escherichia coli (UPEC) strains using pulsed field gel electrophoresis (PFGE).

Method: Escherichia coli (E. coli) strains were recovered from the patients with urinary tract infections (UTI) whom admitted in several major hospitals in Tehran. Antibiotic susceptibility testing was done according to CLSI guideline. The present of some virulence factor have been detected using PCR assay. Genotyping of the strains was performed by PFGE and all PFGE profiles were subjected to data processing.

Result: In total, 60 E. coli strains were subjected to the study. Most of E. coli isolates were resistant to cefepime (100\%) and cephalothin (74\%) and susceptible to imipenem (100\%), vancomycin (100\%) and doxycycline (100\%). Among the UPEC isolates the prevalence of fimbriae type I (fimH), hemolysin (hlyA) and aerobactin (aer) genes were $89 \%, 60 \%$ and $90 \%$, respectively. The PFGE differentiated E. coli strains into 33 different genetic clusters. Majority (30\%) of them including PFGE type 11 generated 15 bands, while PFGE type 2 was the lowest (2\%) prevalent group with 9 bands. Conclusion: The result showed that the antibiotic resistance is escalating rapidly. UPEC strains causing infections are more likely to harbor certain virulence genes. Our finding also showed $E$. coli strains isolated under the study were belonged to the diverse clones.
\end{abstract}

Keywords: Escherichia coli, PFGE, UTIs, Virulence genes

\section{Background}

One of the most common bacterial infections is urinary tract infection (UTI) that accounts for a considerable amount of morbidity and high medical costs and also can lead to significant mortality. While UTI affects men and women it's most common among women except at early infancy. Approximately $90 \%$ of all UTIs in young women are caused by $E$. coli which is a gram-negative, rod-shaped bacterium and a member of the normal intestinal microorganism. Virulence factors are important in severe UTIs $[1,2]$. Some of the virulence genes of UPEC strains are aerobactin (aer), P fimbriae (pap), hemolysin $(h l y)$, type 1 fimbriae, afimbrial adhesin I (afa I),

\footnotetext{
* Correspondence: ranjbarre@gmail.com

Molecular Biology Research Center, Systems Biology and Poisonings Institute, Baqiyatallah University of Medical Sciences, Tehran, Iran
}

cytotoxic necrotizing factor 1 ( $c n f 1)$, S fimbriae (sfa), adhesins and fimbriae. The other virulence genes that have a role in pathogenecity of organism are: kpsMT, ompT, usp, iroN, iha, set 1, astA, group II capsule synthesis; sfalfoc, $\mathrm{S}$ and F1Cfimbriae; iutA, traT, serum resistance; and $\mathrm{fimH}[3-5]$.

In the past recent years, the spectrum and frequency of antimicrobial-resistant UTIs have raised [6, 7]. The resistant patterns of bacteria have been varied by geographical location and by time so periodically testing of antibiotic resistant is really important. E. coli strains are the leading causes of serious bacterial infections in health society and very different antibiotic patterns have been reported based on the source [8,9]. Mobile genetic elements including transposons, plasmids and integrons contribute to lateral transfer of resistance genes in 
bacteria. E. coli can be intrinsically resistant to some special antibiotics and have gens which are responsible for resistance to some of antibiotics such as aminoglycosides, flouroquinolones and $\beta$-lactamas $[10,11]$.

Several studies on various pathotypes of Iranian E. coli isolates have done in which a high level of virulence and antibiotic resistance genes have been reported [1, 12-14].

For identification of bacterial infection sources, it is influential to establish relationships between different isolates of bacteria. It helps to determine the contamination sources, gaining insights into the distribution of pathogens, understanding how much pathogens changed over time, to choose the best treatment of diseases, and reducing the risks of antibiotic resistances [15]. Many different typing methods have been established that have been very useful in describing the epidemiology of infectious diseases. The earlier methods were based on phenotypic typing while modern methods have been based on genome components of bacteria [16, 17]. DNA-based approaches have become potentially powerful methods in microbial typing. These techniques consist of analysis of plasmid profiles [18], RFLP (Restriction Fragment Length Polymorphism) [19], Ribotyping [20, 21], MLST (Multi Locus Sequence Typing) [22], VNTR (Variable Number Tandem Repeat) [23, 24], RAPD (Randomly Amplification of Polymorphic DNA) [25, 26], AP-PCR (Arbitrary Pprimed PCR) [27], Rep-PCR (Repetitive extragenic palindromic) [28], ERIC-PCR (Enterobacterial Repetitive Intergenic Consensus) [29, 30], Microarray [5, 31] and PFGE (Pulsed-Field Gel electrophoresis) [32, 33].

The characteristic of typing methods such as discriminatory power, ease of performance, reproducibility, ease of interpretation, and the cost is really important to gain appropriate results. A broad range of methods used to type E. coli but PFGE is a commonly used technique for generating DNA fingerprints $[28,34]$. PFGE is nominated as the gold standard technique for typing foodborne bacteria $[35,36]$. We aimed the current study to determine antibiotic resistance and genotyping of uropathogenic E. coli strains isolated from the patients with urinary tract infections in Tehran.

\section{Method}

The uropathogenic E. coli isolates were collected from several major hospitals in Tehran during May to November 2016. The bacterial isolates were identified as $E$. coli by standard microbiological and biochemical method. The growth of a single colony with counts $>10^{5}$ colony forming unit/ml were considered as positive urine cultures. All E. coli isolates were inoculated on MacConkey agar then incubated for $24 \mathrm{~h}$ at $37{ }^{\circ} \mathrm{C}$. The typical purple colonies were then streaked on Eosin Methylene Blue (EMB) agar plates and were incubated for $20 \mathrm{~h}$ at $37{ }^{\circ} \mathrm{C}$. Those colonies with metallic green morphology were subjected to biochemical tests, including hydrogen sulfide, citrate, urease and indol [13].

\section{Antimicrobial susceptibility testing}

Antimicrobial susceptibility was tested by the KirbyBauer disk diffusion method. Antimicrobial agents tested were amikacin $(30 \mu \mathrm{g})$, cephalexin $(10 \mu \mathrm{g})$, ciprofloxacin $(5 \mu \mathrm{g})$, cefalothin $(30 \mu \mathrm{g})$, cefexime $(5 \mu \mathrm{g})$, cefpodoxime $(10 \mu \mathrm{g})$, cephazolin $(30 \mu \mathrm{g})$, cefepime $(30 \mu \mathrm{g})$, doxycycline $(10 \mu \mathrm{g})$, nitrofurantoin $(30 \mu \mathrm{g})$, gentamycine $(10 \mu \mathrm{g})$, nalidixic acid $(30 \mu \mathrm{g})$, norfloxacin $(5 \mu \mathrm{g})$, cotrimoxazole $(30 \mu \mathrm{g})$, tetracycline $(30 \mu \mathrm{g})$, imipenem $(10 \mu \mathrm{g})$, and vancomycin $(30 \mu \mathrm{g})$. These antibiotics belong to $\beta$-lactamas, glycopeptides, aminoglycosides, quinolones and tetracycline classes [10]. The resistance to above mentioned antibiotics was determined according to the breakpoint proposed by CLSI [37]. For quality-control $E$. coli ATCC $^{\oplus} 25,922^{\text {TM }}$ was used.

\section{Detection of virulence factor}

Genomic DNA of UPEC isolates were extracted using DNA extraction kit (AccuPrep ${ }^{\circledR}$ Genomic DNA Extraction Kit, Bioneer, South Korea), after preparation cultured cells with PBS buffer. Binding buffer (GC) was mixed with the samples and incubated for $10 \mathrm{~min}$ at $60^{\circ}$ $\mathrm{C}$ then washing buffers were added and samples were spined according to the manufacturer's instructions. Then elution buffer was added to the genomic DNA and stored at $-20{ }^{\circ} \mathrm{C}$.

All UTI isolates were screened for carriage of $\mathrm{fimH}$, $h l y A$ and aer virulence factors. PCR assays were used to reveal the prevalence of these virulence genes using specific primers. The amplification reaction were carried out in a final volume of $25 \mu \mathrm{l}$ containing $200 \mu \mathrm{M}$ of deoxynucleotide triphosphates (dNTPs), $2.5 \mu \mathrm{l}$ of $10 \mathrm{X}$ PCR buffer, $0.7 \mathrm{mg} / \mu \mathrm{l} \mathrm{MgCl}_{2}, 0.6$ units of Taq polymerase, 10 pmol of each primer, and $2 \mu$ of sample DNA. The PCR products were analyzed with gel electrophoresis on $2 \%$ agarose, followed by staining with $\mathrm{EtBr}$ solution after $1 \mathrm{~h}$ under $80 \mathrm{v}$ and visualized using an ultraviolet (UV) transilluminator. Primer sequences and PCR machine conditions are shown in Table 1.

\section{Pulsed field gel electrophoresis procedure}

All the PFGE steps were accomplished following the CDC-standardized procedure used by all PulsedNet laboratories with some changes [38]. Colonies from an overnight culture were suspended in TE buffer $(5 \mathrm{mmol} /$ liter Tris-HCL [pH 8.0] $1 \mathrm{M}, 10 \mathrm{mmol} / \mathrm{liter}$ EDTA $0.5 \mathrm{M})$ at a wavelength of $600 \mathrm{~nm}(\mathrm{OD}=0.8-1.2)$. Then proteinase $\mathrm{K}, 20 \mathrm{mg} / \mathrm{ml}$ added to suspension and mixed with sodium dodecyl sulphate and 1\% melted SeaKem Gold agarose and pipette into plug moulds and left at $4{ }^{\circ}$ C. After solidation, each plug was transferred to a falcon 
Table 1 Primers and cycling conditions for the PCR assays

\begin{tabular}{|c|c|c|c|c|}
\hline Gene & Primer sequence & Size (bp) & Cycling condition & Reference \\
\hline hlyA & $\begin{array}{l}\text { F: AACAAGGATAAGCACTGTTCTGGCT } \\
\text { R: ACCATATAAGCGGTCATTCCCGTCA }\end{array}$ & 1177 & $\begin{array}{l}1 \text { cycle of } 95^{\circ} \mathrm{C} \text { for } 5 \text { min; } 30 \text { cycles of } 94{ }^{\circ} \mathrm{C} \text { for } 1 \mathrm{~min}, 64^{\circ} \mathrm{C} \text { for } 1 \mathrm{~min} \text {, } \\
72^{\circ} \mathrm{C} \text { for } 1 \mathrm{~min} ; 72{ }^{\circ} \mathrm{C} \text { for } 8 \mathrm{~min} \text { final extension }\end{array}$ & [58] \\
\hline $\mathrm{FimH}$ & $\begin{array}{l}\text { F:GAGAAGAGGTTTGATTAAACTTATTG } \\
\text { R: AGAGCCGCTGTAGAACTGAGG }\end{array}$ & 559 & $\begin{array}{l}1 \text { cycle of } 95^{\circ} \mathrm{C} \text { for } 5 \mathrm{~min} ; 30 \text { cycles of } 94{ }^{\circ} \mathrm{C} \text { for } 1 \mathrm{~min}, 60^{\circ} \mathrm{C} \text { for } 1 \mathrm{~min} \text {, } \\
72{ }^{\circ} \mathrm{C} \text { for } 1 \mathrm{~min} ; 72{ }^{\circ} \mathrm{C} \text { for } 8 \text { min final extension }\end{array}$ & {$[60]$} \\
\hline aer & $\begin{array}{l}\text { F: GCTGGGCAGCAAACTGATAACTCTC } \\
\text { R: CATCAAGCTGTTGTTCGTCCGCCG }\end{array}$ & 602 & $\begin{array}{l}1 \text { cycle of } 95^{\circ} \mathrm{C} \text { for } 5 \text { min; } 30 \text { cycles of } 94^{\circ} \mathrm{C} \text { for } 1 \mathrm{~min}, 62^{\circ} \mathrm{C} \text { for } 1 \mathrm{~min} \text {, } \\
72^{\circ} \mathrm{C} \text { for } 1 \text { min; } 72{ }^{\circ} \mathrm{C} \text { for } 8 \text { min final extension }\end{array}$ & [58] \\
\hline
\end{tabular}

containing $5 \mathrm{ml}$ cell lysis buffers $(2.5 \mathrm{ml}$ Tris-HCL [pH 8.0] $1 \mathrm{M}, 5 \mathrm{ml}$ EDTA $0.5 \mathrm{M}, 5 \mathrm{ml}$ Sarcosyl 10\%) and proteinase $\mathrm{K}$ and then incubate overnight at $52{ }^{\circ} \mathrm{C}$. The plugs were washed three times for $30 \mathrm{~min}$ in sterile distilled water and twice for $30 \mathrm{~min}$ in TE buffer at $52{ }^{\circ} \mathrm{C}$ on an orbital shaker. $2 \mathrm{~mm}$ of $E$. coli colonies plugs were digested overnight with $50 \mathrm{U}$ of $\mathrm{XbaI}$ restriction enzyme. And Salmonella Braenderup $\mathrm{H} 2812$ was used as size standard which after digestion with XbaI generates fragments ranging from 20.5 to $1135 \mathrm{~kb}$ and cover the fragment ranges generated by E. coli strains [39].

After restriction digestion the plugs were placed in refrigerator for $30 \mathrm{~min}$. PFGE was performed with the CHEF DR-III (Bio-Rad Laboratories) system using a 1\% Ultra pure agarose gel in 210.5 TBE (Tris-base, EDTA, boric acid). The electrophoresis condition were set as follows: initial switch time, $2.2 \mathrm{~s}$, final switch time, $54.2 \mathrm{~s}$, run time $20 \mathrm{~h}$, include angle $120^{\circ}$, gradient, $6 \mathrm{~V} / \mathrm{cm}$, temperature, $14{ }^{\circ} \mathrm{C}$. The gel was stained for $30 \mathrm{~min}$ with $\mathrm{EthBr}, 0.5 \mathrm{mg} / \mathrm{ml}$ and then the fingerprinting profile was observed by Uvitec system by illuminated UV wave to the gel.. The PFGE profiles were compared using In silico stimulation of molecular experiment with a dice similarity coefficient and UPGMA analysis to create the dendrogram. To analyze genetic relatedness, cut off line at $85 \%$ was considered [38-41].

\section{Results}

\section{Bacterial isolates and antibiotic susceptibility testing}

Over 6-month period, a total of $60 \mathrm{E}$. coli strains were isolated and subjected to this study. Distribution of the isolates based on patient's gender and location in Tehran is shown in Table 2. As it is represented in Fig. 3, these 60 isolates identified to be multidrug resistant (MDR). The different prevalence of each antibiotic resistance was as follows: cefepime (100\%), cefalothin $(74 \%)$, cefpodexime (67\%), nalidixic acid (63\%), cotrimoxazole (54\%), cefixime (50\%), cephazolin $(50 \%)$, tetracycline $(50 \%)$, norfloxacin (43\%), ciprofloxacin (34\%), cephalexin (30\%), gentamycin (19\%), nitrofurantoin (10\%), amikacin (8\%), doxycycline (0\%), imipenem (0\%), and vancomycin (0\%). (Table. 2$)$.

\section{PCR assay}

The PCR amplified successfully aer, fimH and $h l y A$ genes with 602 bp, 559 bp and 1177 bp amplicons respectively. The PCR results of some representative isolates are shown in Fig. 1. Among 60 UPEC isolates, aer was the most prevalent virulence gene $(n=54,90 \%)$ followed by fimH $(n=53,89 \%)$ and $h l y A(n=36,60 \%)$. All of the isolates carried at least one virulence gene.

\section{Pulsed field gel electrophoresis}

After observing PFGE profiles fingerprinting (Fig. 2), clustering analysis performed and 33 PFGE pulsotypes were detected for $E$. coli isolates as seen in the dandrogram (Fig. 3). Eighteen clusters including (pulsotypes $2,3,9,11,16,17$ and 21 ) were consist of only one strain, 9 clusters including (pulsotypes 7,14,29 and 31) consist of 2 strains, 2 clusters including (pulsotypes13and 26) consist of 3 strains, 2 clusters including (pulsotypes1 and 19) consist of 4 strains, and 2 clusters including (pulsotypes 12 and 22) consist of 5 strains. Distribution of the pulsutypes is shown in Table 2 .

\section{Discussion}

E. coli is considered as the cause of $80-90 \%$ of UTIs that today is one of the most common bacterial infections [42]. Because of unreasonable use of antibiotics, the bacterial resistance has been raised. In this study, we reported a high value of multidrug resistance among the uropathogenic E. coli strains. Resistance to cefepime was very high (100\%) and after that the strains were resistant to cefalothin (74\%) and cefpodoxime (67\%). Also high sensitivity to imipenem, vancomycin and doxycycline (100\%), amikacin (92\%) and nitrofurantoin (90\%) have been observed. High levels of susceptibility to imipenem, amikacin, nitrofurantoin and also high levels of resistance to tetracycline and ampicilline have been reported in other studies in Iran $[6,13]$.

Our results in some cases are consistent with those reported by Niranjan and Malini. They evaluated antibiotic resistance of $119 \mathrm{E}$. coli isolated from UTI patients. The isolates were resistant to ampicillin (88.4\%), amoxicillin (74.4\%), norfloxacin (74.2\%), ceftiriaxone (71.4\%) and sensitive to amikacin (82.6\%), nitrofurantoin (82.1\%) and imipenem (98.9\%) [43].

No resistance to vancomycin, imipenem and doxycycline was observed among the studied isolates. In previous studies a high sensitivity to imipenem has been also 
Table 2 Date of isolation, age, sex and location of patients admitted to the hospital; isolates divided in different pulsotype

\begin{tabular}{|c|c|c|c|c|c|}
\hline Pulsotype & Isolation(NO.) & Sex & Age(year) & Patient location & Date of isolation \\
\hline \multirow[t]{4}{*}{1} & $13 u$ & $\mathrm{~F}$ & 27 & North & $30 / 05 / 2016$ \\
\hline & $8 u$ & $\mathrm{~F}$ & 79 & North & 18/05/2016 \\
\hline & $84 u$ & $\mathrm{~F}$ & 52 & Northeast & 26/05/2016 \\
\hline & $94 u$ & $\mathrm{~F}$ & 20 & Northeast & 18/07/2016 \\
\hline 2 & $30 u$ & $\mathrm{~F}$ & 41 & West & $22 / 11 / 2016$ \\
\hline 3 & $4 u$ & $\mathrm{~F}$ & 24 & Center & $25 / 11 / 2016$ \\
\hline 4 & $6 u$ & $\mathrm{~F}$ & 63 & West & 10/10/2016 \\
\hline \multirow[t]{2}{*}{5} & $21 u$ & M & 55 & West & 06/08/2016 \\
\hline & $23 u$ & M & 62 & West & 23/08/2016 \\
\hline 6 & $7 u$ & $\mathrm{~F}$ & 26 & North & $11 / 07 / 2016$ \\
\hline \multirow[t]{2}{*}{7} & $28 u$ & $\mathrm{~F}$ & 52 & Center & 14/09/2016 \\
\hline & $9 u$ & $\mathrm{~F}$ & 87 & Center & 23/10/2016 \\
\hline \multirow[t]{2}{*}{8} & $59 u$ & $\mathrm{~F}$ & 34 & East & 18/05/2016 \\
\hline & $73 u$ & $\mathrm{~F}$ & 56 & East & 13/10/2016 \\
\hline 9 & $72 \mathrm{u}$ & $\mathrm{F}$ & 78 & North & 18/09/2016 \\
\hline \multirow[t]{2}{*}{10} & $100 u$ & $\mathrm{~F}$ & 74 & East & 06/08/2016 \\
\hline & $19 u$ & M & 71 & Northeast & 10/08/2016 \\
\hline 11 & $71 u$ & M & 68 & Center & 18/05/2016 \\
\hline \multirow[t]{5}{*}{12} & $10 \mathrm{u}$ & M & 47 & Northwest & 03/06/2016 \\
\hline & $5 u$ & M & 56 & Northwest & 01/07/2016 \\
\hline & $82 u$ & $\mathrm{~F}$ & 48 & Northwest & 29/06/2016 \\
\hline & $24 u$ & $\mathrm{~F}$ & 39 & North & 03/07/2016 \\
\hline & $31 u$ & $\mathrm{~F}$ & 72 & North & 03/07/2016 \\
\hline \multirow[t]{3}{*}{13} & $12 u$ & $\mathrm{~F}$ & 68 & North & 05/09/2016 \\
\hline & $32 u$ & M & 70 & West & $12 / 09 / 2016$ \\
\hline & $11 u$ & $\mathrm{~F}$ & 29 & West & 03/09/2016 \\
\hline \multirow[t]{2}{*}{14} & $62 u$ & M & 82 & East & 28/10/2016 \\
\hline & $81 u$ & M & 74 & Northeast & 20/10/2016 \\
\hline \multirow[t]{2}{*}{15} & $58 u$ & M & 68 & North & $16 / 11 / 2016$ \\
\hline & $60 u$ & $\mathrm{~F}$ & 50 & North & $11 / 11 / 2016$ \\
\hline 16 & $70 u$ & $\mathrm{~F}$ & 73 & Center & $11 / 07 / 2016$ \\
\hline 17 & $79 u$ & $\mathrm{~F}$ & 59 & Northwest & 18/07/2016 \\
\hline 18 & $83 u$ & $\mathrm{~F}$ & 54 & Northwest & 26/05/2016 \\
\hline \multirow[t]{4}{*}{19} & $20 u$ & M & 71 & Northwest & 18/09/2016 \\
\hline & $89 u$ & M & 67 & North & $30 / 07 / 2016$ \\
\hline & $92 u$ & $\mathrm{~F}$ & 49 & Center & 22/08/2016 \\
\hline & $97 u$ & $\mathrm{~F}$ & 59 & Center & $10 / 08 / 2016$ \\
\hline 20 & $14 u$ & M & 64 & Northeast & 06/08/2016 \\
\hline 21 & $80 u$ & $\mathrm{~F}$ & 40 & East & $11 / 10 / 2016$ \\
\hline \multirow[t]{5}{*}{22} & $16 u$ & $\mathrm{~F}$ & 24 & Northeast & 28/10/2016 \\
\hline & $18 u$ & M & 66 & Northeast & 18/10/2016 \\
\hline & $74 u$ & F & 27 & Northeast & 23/09/2016 \\
\hline & $76 u$ & $\mathrm{~F}$ & 46 & West & $22 / 10 / 2016$ \\
\hline & $25 u$ & $\mathrm{~F}$ & 38 & West & 18/10/2016 \\
\hline
\end{tabular}


Table 2 Date of isolation, age, sex and location of patients admitted to the hospital; isolates divided in different pulsotype (Continued)

\begin{tabular}{|c|c|c|c|c|c|}
\hline Pulsotype & Isolation(NO.) & Sex & Age(year) & Patient location & Date of isolation \\
\hline \multirow[t]{3}{*}{23} & $86 u$ & M & 53 & West & $24 / 05 / 2016$ \\
\hline & $87 u$ & F & 36 & North & $26 / 05 / 2016$ \\
\hline & $93 \mathrm{u}$ & M & 83 & North & 26/05/2016 \\
\hline 24 & $15 u$ & F & 27 & Center & 25/08/2016 \\
\hline 25 & $99 u$ & $F$ & 70 & Center & $14 / 08 / 2016$ \\
\hline \multirow[t]{2}{*}{26} & $17 u$ & $\mathrm{~F}$ & 36 & West & 25/09/2016 \\
\hline & $26 u$ & M & 68 & West & 23/09/2016 \\
\hline 27 & $78 u$ & $\mathrm{~F}$ & 24 & Center & $11 / 10 / 2016$ \\
\hline \multirow[t]{2}{*}{28} & $2 u$ & $\mathrm{~F}$ & 77 & Northeast & $25 / 05 / 2016$ \\
\hline & $3 u$ & M & 68 & Northeast & $17 / 08 / 2016$ \\
\hline 29 & $35 u$ & $\mathrm{~F}$ & 74 & Center & 15/07/2016 \\
\hline 30 & $88 u$ & $\mathrm{~F}$ & 31 & Center & 11/07/2016 \\
\hline \multirow[t]{2}{*}{31} & $61 \mathrm{u}$ & $\mathrm{F}$ & 26 & North & $24 / 06 / 2016$ \\
\hline & $98 u$ & $\mathrm{~F}$ & 47 & North & 13/06/2016 \\
\hline 32 & $77 u$ & $\mathrm{~F}$ & 33 & Center & $11 / 10 / 2016$ \\
\hline 33 & $85 u$ & $\mathrm{~F}$ & 33 & West & $30 / 05 / 2016$ \\
\hline
\end{tabular}

reported [43-46]. These antibiotics seems to be a good choice for the treatment of UTI caused by $E$. coli but it should be considered that unlimited use of these antibiotics can gradually lead to increasing antibiotic resistant. Shakya, did a research on antibiotic resistance of E. coli strains isolated from Indian children. The results showed that the strains have been resistant to nalidixic acid (45\%), tetracycline (37\%), ampicillin (37\%), trimetho$\mathrm{prim} /$ sulfamethoxazole (29\%), amoxicillin/clavulanic acid (29\%), imipenem (0.0\%) [45].

Susceptibility to amikacin in our study was high as it was in studies carried out in other parts of the world $[43,46,47]$. However, the resistance to tetracycline in our study was $50 \%$ while in another study it was reported to be $26 \%$ [48].

In the present study, it has been shown that resistant to gentamicin (19\%) and nitrofurantoein (10\%) was low among E. coli isolates and it was partially similar to the study reported by Adib and his colleagues. They showed that $54.16 \%$ of the isolates were resistant to nalidixic acid, $36.45 \%$ to gentamycin, $71 \%$ to cefazolin, $29.18 \%$ to ciprofloxacin, $14.58 \%$ to cefepime, $6.25 \%$ to nitrofurantoin, and $0.0 \%$ to imipenem [44]. However in other studies the resistance against gentamycin for E.coli isolates in Iran was about $93 \%$ and $62 \%[12,14]$. Villar et al. reported $99 \%$ and 98 susceptibility to imipenem and amikacin respectively for their uropathogenic $E$. coli strains that is consistent with our results [46].

In this study, we have shown the presence of aer, fimH and hylA genes in UPEC isolates (Fig. 3). Almost all of the isolates harbored aer gene, which is responsible for obtaining iron. The frequency of aer gene in our study is higher than recent studies $[49,50]$.One of the secreted toxine factors in E. coli strains is $h l y A$, which implicated in tissue damage and dysfunction of local immune responses. This study showed a higher prevalence of hlyA among UPEC strains in contrast to other studies $[49,50]$. Of note, FimH is highly conserved and extremely common among E. coli isolates. FimH mediates UPEC adherence to the urothelium cells, and helps the
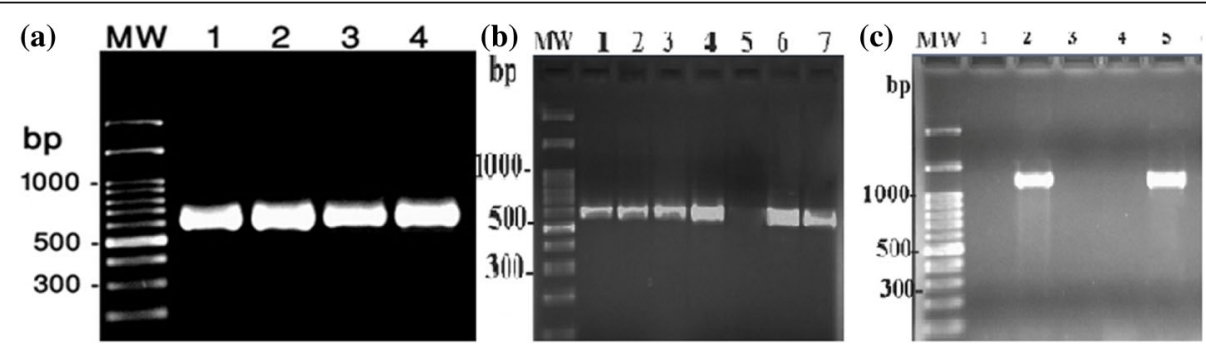

Fig. 1 Detection of aer (a), hly A (b) and fim $H$ (c) gens in some representative E. coli isolates 


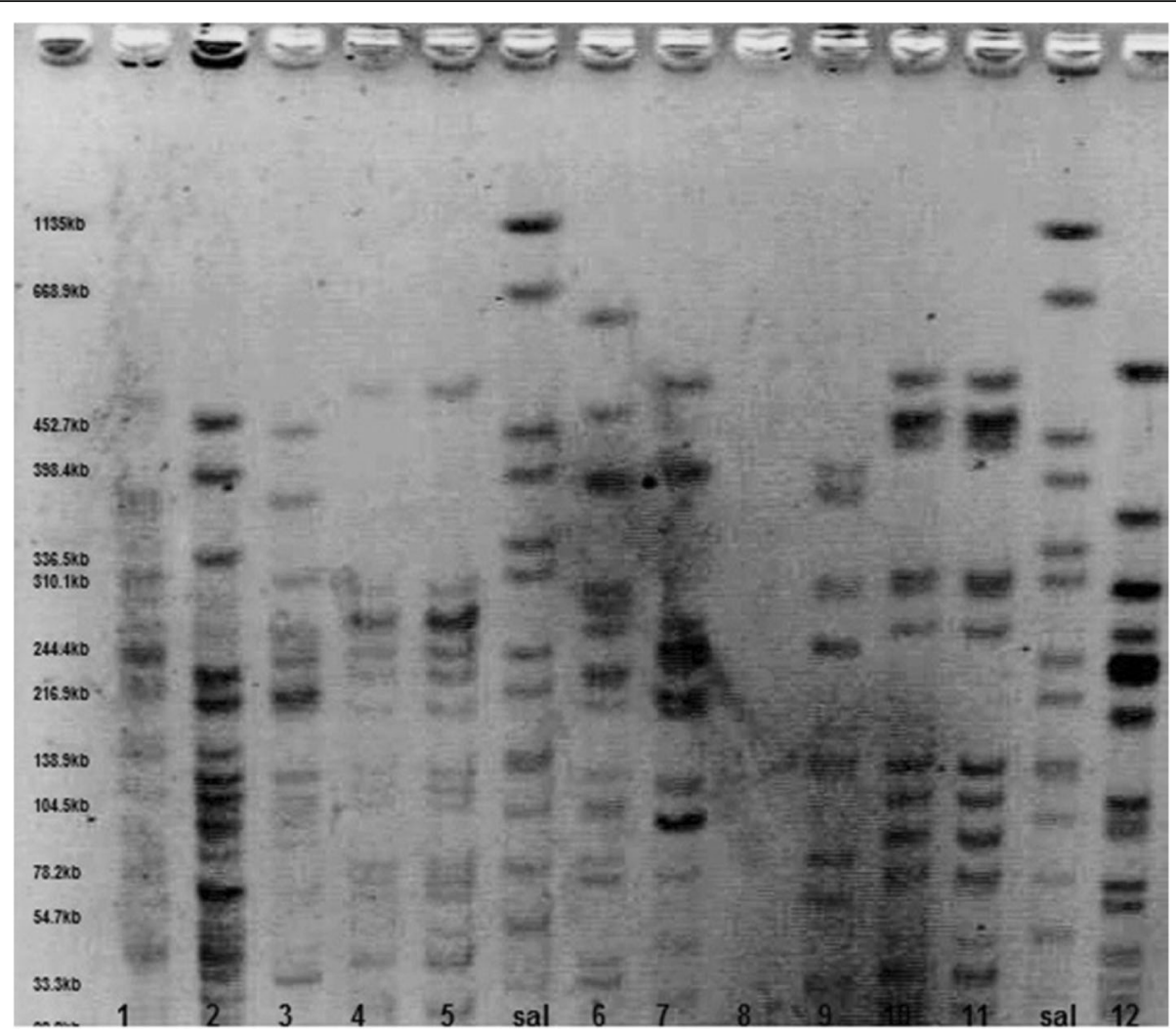

Fig. 2 Representative PFEG profiles of some E. coli strains; Salmonella Braenderup used as molecular size standard (1135-28.8 kb)

formation of intracellular bacterial biofilms [51]. The distribution of $\mathrm{fimH}$ gene in our strains is in agreement with other published data $[1,49,52]$.

Information about the source of the infections and relatedness between bacterial agents is helpful for preventing measures and choosing the best treatment [35]. In recent studies PFGE, as a gold standard method, has been used for DNA fingerprinting and epidemiologic studies successfully. PFGE is a high discriminatory and reproducible typing method that is used in CDC laboratories $[34,53]$. This study provides more information on the distribution of urinary isolates of $E$. coli strains. We applied PFGE technique for separating fragments of DNA chromosome digested using XbaI restriction enzyme. This enzyme has been proved to be more powerful and it is the most common used restriction enzyme for UPEC outbreaks [54-56], and was successfully used in this study to discriminate between the isolates from the UTI patients in some major hospital in Tehran. By using Xbal enzyme the analyzed isolates generated an exclusive profile with the number of DNA bands between 9 and15 and the bands from $33.3 \mathrm{kbp}$ to $1135 \mathrm{kpb}$, while other studies have shown different number of bands and different molecular weights. Anvarinejad et al. reported 9 to 16 DNA bands with molecular size of 2 to $660 \mathrm{kbp}$ in molecular typing of $E$. coli isolates from patients with cyctitis and pyelonephritis [57]. Dong et al. reported 15-20 distinct bands in genotyping of Shiga toxin produced by $E$. coli isolates [41]. Ejrnaes et al. reported $15-20$ bands with $50 \mathrm{kbp}$ to $1200 \mathrm{kbp}$ molecular sizes by typing UPEC strains [8].

In the current study, based on drown dendrogram 33 clusters with $85 \%$ similarity were found among 60 isolates. The strains with 12 and 15 bands had the highest percentage of $30 \%$ and $25 \%$ respectively, and the lowest percentage was for the strains with the $9(2 \%)$. The pattern No. 10 with 12 bands and No. 12 with 15 bands were repeated more than other patterns in the present study (Fig. 2). By considering the distinct pulsotypes obtained in this study it seems that there is genetic heterogeneity of $E$. coli in the region. Of note, between 60 MDR isolates collected from 6 different locations in Tehran $84 \%$ of isolates belonged to the Center had specific types and $16 \%$ of isolates of North and Northwest had similar PFGE patterns, while in Northeast only 30\% of isolates had specific patterns and other types were also found in other locations during 6 month of study. There was no defined pattern between the time of collection and PFGE profiles of E. coli isolates. Patrick and Padman investigated the efficacy of PFGE in a study of 


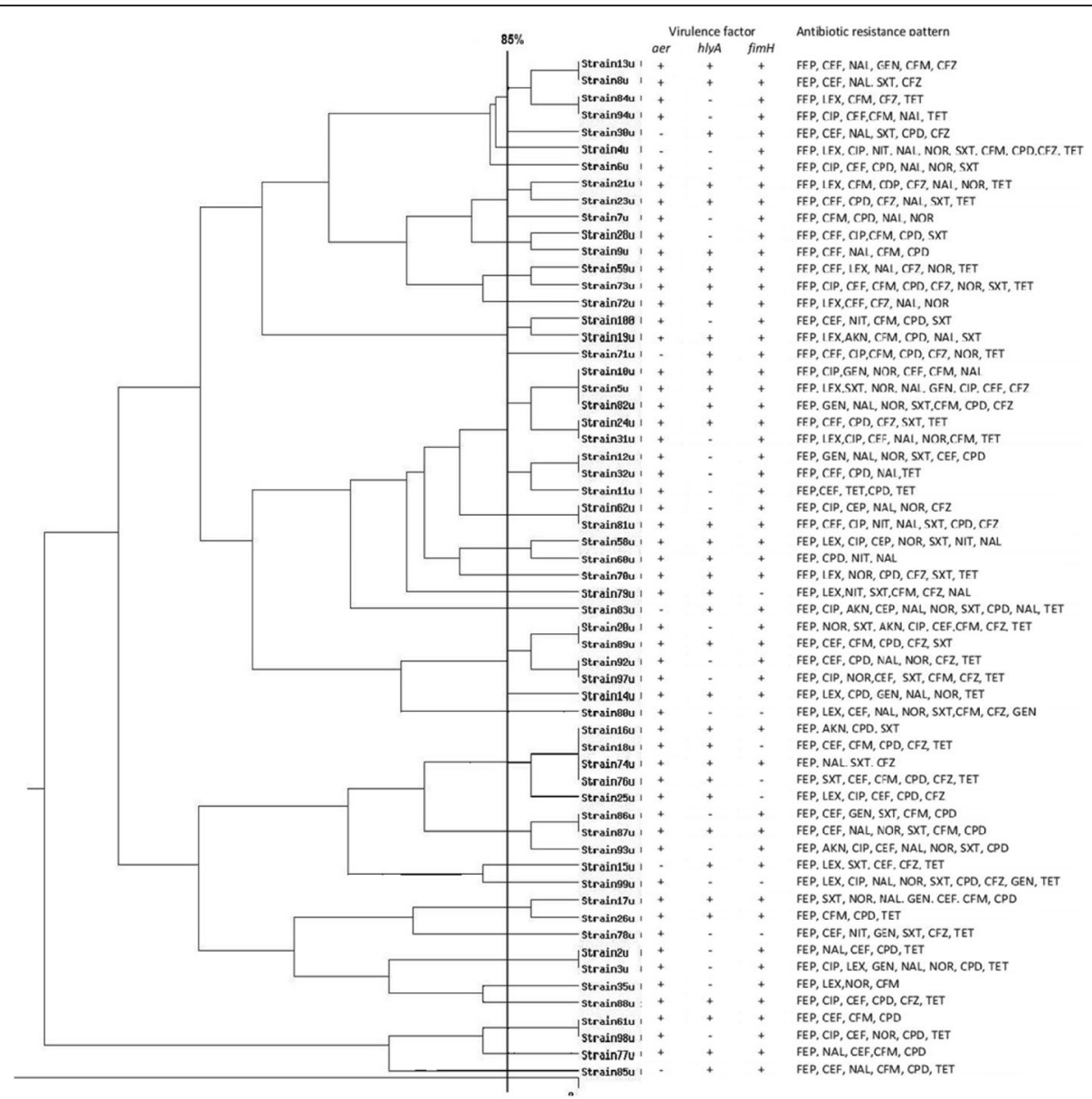

Fig. 3 Dendrogram of 60 E. coli isolates based on PFGE patterns after digestion with enzyme Xbal associated with present of virulence factors (fimH, hlyA and aer) and antibiotic resistance pattern; AKN, amikacin; LEX, cephalexin; CIP, ciprofloxacin; CEF, cefexime; CDP, cefpodexim; CFZ, cephazolin; FEP, cefepime; NIT, nitrofurantoin; GEN, gentamycin; NAL, nalidixic acid; NOR, norfloxacin; SXT, cotrimoxazole; TET, tetracyclin

extended spectrum beta lactamase (ESBL) enzymes produced by pathogen (Escherichia coli and klebsiella pneumonia) [53]. Miyuki and his colleagues used PFGE-CHEF for epidemiological study of E. coli O157: H7 isolates collected from 1997 to 2000 in Northern Ireland and compared the results to phage typing analysis. They reported that PFGE-CHEF typing proved to have a greater ability to distinguish E. coli $\mathrm{O} 157$ isolates, while phage typing has been shown to be less efficient [58]. Jones et al. used PFGE for determining the presence of E. coli $\mathrm{O}_{157}$ and Salmonella isolates in an outbreak and concluded that $20 \%$ of clusters were attributed to the same source [59]. Xiaoli et al. in China did a study about the genotypic characteristic of multidrug-resistance UTIs E. coli by PFGE. Forty PFGE types were observed for 51 MDR E. coli isolates at the cut off value of $85 \%$ [40].

Considering the high diversity of genetic relatedness between our MDR isolates there was not special pattern for antibiotic resistant. However, we found that isolates belonging to pulsotype 3 were resistant to $65 \%$ of antibiotics, while isolates in pulsotype 29 were resistant to $23 \%$ of antibiotics.

\section{Conclusion}

The present study demonstrates that considering the high number of $E$. coli types in the previous studies our conclusions are not surprising. The PFGE applied in the study was shown to be more powerful. PFGE is an appropriate choice for identifying the sources, clonal relatedness and spread of $E$. coli isolates in the hospitals. The result showed that the antibiotic resistance among uropathogenic $E$. coli under study is escalating rapidly. The PFGE types 3, 18, 25 that consist of $5 \%$ of isolates were more associated with antimicrobial resistant. Despite some exception such as PFGE type 1 and 22, most of the isolates in the same type followed similar virulence factors pattern. The information obtained from the similarity of the pulsotypes among isolates can help physicians to understand antibiotic resistant patterns of the different isolates from different sources and have a correct choice in prescribing antibiotic medicine. 


\section{Acknowledgements}

We would like to thank from the "Clinical Research Development Center of Baqiyatallah hospital" for their kindly cooperation. This study was supported financially by "Clinical Research Development Center of Baqiyatallah hospital".

\section{Availability of data and materials}

All data generated or analyzed during this study are included in this published article.

\section{Authors' contribution}

MR performed laboratory works, analyzed the data and drafted the paper. RR designed the study, interpreted the data and revised the manuscript. All authors read and approved the final manuscript.

\section{Ethics approval and consent to participate}

Not applicable.

\section{Consent for publication}

Not applicable.

\section{Competing interests}

The authors declare that they have no competing interests.

\section{Publisher's Note}

Springer Nature remains neutral with regard to jurisdictional claims in published maps and institutional affiliations.

Received: 17 November 2017 Accepted: 18 September 2018 Published online: 03 October 2018

\section{References}

1. Momtaz H, et al. Uropathogenic Escherichia coli in Iran: serogroup distributions, virulence factors and antimicrobial resistance properties. Ann Clin Microbiol Antimicrob. 2013;12(1):8.

2. Johnson JR. Virulence factors in Escherichia coli urinary tract infection. Clin Microbiol Rev. 1991;4(1):80-128.

3. Soto $S$, et al. Prevalence of the set-1B and astA genes encoding enterotoxins in uropathogenic Escherichia coli clinical isolates. Microb Pathog. 2009;47(6):305-7.

4. Bauer RJ, et al. Molecular epidemiology of 3 putative virulence genes for Escherichia coli urinary tract infection-usp, iha, and iroNE. coli. J Infect Dis. 2002;185(10):1521-4.

5. Jahandeh $\mathrm{N}$, et al. Uropathogenic Escherichia coli virulence genes: invaluable approaches for designing DNA microarray probes. Central European journal of urology. 2015;68(4):452.

6. Farshad, S., et al., Microbial susceptibility, virulence factors, and plasmid profiles of uropathogenic Escherichia coli strains isolated from children in Jahrom, Iran. Archives of Iranian Medicine (AIM), 2012. 15(5).

7. Tajbakhsh E, et al. Prevalence of class 1 and 2 integrons in multi-drug resistant Escherichia coli isolated from aquaculture water in Chaharmahal Va Bakhtiari province, Iran. Ann Clin Microbiol Antimicrob. 2015;14(1):37.

8. Ejrnaes $K$, et al. Pulsed-field gel electrophoresis typing of Escherichia coli strains from samples collected before and after Pivmecillinam or placebo treatment of uncomplicated community-acquired urinary tract infection in women. J Clin Microbiol. 2006:44(5):1776-81.

9. Anderson KL, Whitlock JE, Harwood VJ. Persistence and differential survival of fecal indicator bacteria in subtropical waters and sediments. Appl Environ Microbiol. 2005;71(6):3041-8.

10. Davies J, Davies D. Origins and evolution of antibiotic resistance. Microbiology and Molecular Biology Reviews : MMBR. 2010;74(3):417-33.

11. Blair JMA, et al. Molecular mechanisms of antibiotic resistance. Nat Rev Microbiol. 2014:13:42.

12. Ranjbar $R$, et al. Shiga (Vero)-toxin producing Escherichia coli isolated from the hospital foods; virulence factors, o-serogroups and antimicrobial resistance properties. Antimicrobial Resistance \& Infection Control. 2017:6(1):4

13. Heidary M, Momtaz H, Madani M. Characterization of Diarrheagenic antimicrobial resistant Escherichia coli isolated from pediatric patients in Tehran. Iran Iranian Red Crescent Medical Journal. 2014;16(4):e12329.
14. Momtaz H, et al. Serogroups, virulence genes and antibiotic resistance in Shiga toxin-producing Escherichia coli isolated from diarrheic and nondiarrheic pediatric patients in Iran. Gut Pathogens. 2013;5(1):39.

15. Singh A, et al. Application of molecular techniques to the study of hospital infection. Clin Microbiol Rev. 2006;19(3):512-30.

16. Rivas, L., et al., Typing and Subtyping Methods for Pathogenic Escherichia coli, in Detection and Typing Strategies for Pathogenic Escherichia coli. 2015, Springer. p. 67-99.

17. Ranjbar $\mathrm{R}$, et al. Typing methods used in the molecular epidemiology of microbial pathogens: a how-to guide. The new microbiologica. 2014;37(1):1-15.

18. Ranjbar $\mathrm{R}$, et al. Isolation of clinical strains of Pseudomonas aeruginosa harboring different plasmids. Pakistan journal of biological sciences: PJBS. 2007:10(17):3020-2.

19. Arjomandzadegan $M$, et al. Prevalence of mutations at codon 463 of katg gene in MDR and XDR clinical isolates of mycobacterium tuberculosis in Belarus and application of the method in rapid diagnosis. Acta Microbiol Immunol Hung. 2011:58(1):51-63.

20. Ranjbar $\mathrm{R}$, et al. Increased isolation and characterization of Shigella sonnei obtained from hospitalized children in Tehran, Iran. Journal of health, population, and nutrition. 2008;26(4):426.

21. Ranjbar R, et al. Characterization of endemic Shigella boydii strains isolated in Iran by serotyping, antimicrobial resistance, plasmid profile, ribotyping and pulsed-field gel electrophoresis. BMC research notes. 2008;1(1):74.

22. Ranjbar R, Elhaghi P, Shokoohizadeh L. Multilocus Sequence Typing of the Clinical Isolates of Salmonella Enterica Serovar Typhimurium in Tehran Hospitals. Iranian Journal of Medical Sciences. 2017:41(2).

23. Ranjbar $\mathrm{R}$, Memariani M, Memariani $H$. Diversity of variable number tandem repeat loci in Shigella species isolated from pediatric patients. International journal of molecular and cellular medicine. 2015;4(3):174.

24. Ranjbar $R$, et al. Distribution of virulence genes and genotyping of CTX-M15-producing Klebsiella pneumoniae isolated from patients with communityacquired urinary tract infection (CA-UTI). Microb Pathog. 2016;100:244-9.

25. Pourshafie $M$, et al. Dissemination of a single Vibrio cholerae clone in cholera outbreaks during 2005 in Iran. J Med Microbiol. 2007;56(12):1615-9.

26. Sadeghifard, N., R. Ranjbar, and J. Zaeimi, Antimicrobial susceptibility, plasmid profiles, and RAPD-PCR typing of Acinetobacter bacteria. 2011.

27. Ranjbar R, et al. Molecular characterisation of epidemic isolates of Vibrio cholerae 01 recovered from an outbreak occurred in different parts of Iran in 2005. Clinical Microbiology \& Infection. 2009;15(4):S371.

28. Ranjbar R, et al. Genomic fingerprints of Escherichia coli strains isolated from surface water in Alborz province, Iran. BMC research notes. 2017;10(1):295.

29. Ranjbar R, Ghazi FM. Antibiotic sensitivity patterns and molecular typing of Shigella sonnei strains using ERIC-PCR. Iran J Public Health. 2013;42(10):1151.

30. Hosseini MJ, Kaffashian AR. An outbreak of shigellosis due to Shigella flexneri serotype 3a in a prison in Iran. Archives of Iranian medicine. 2010;13(5):413.

31. Khakabimamaghani $\mathrm{S}$, et al. GelClust: a software tool for gel electrophoresis images analysis and dendrogram generation. Comput Methods Prog Biomed. 2013;111(2):512-8

32. Pooideh $\mathrm{M}$, et al. Molecular Epidemiology of Mycobacterium tuberculosis Isolates in 100 Patients With Tuberculosis Using Pulsed Field Gel Electrophoresis. Jundishapur journal of microbiology. 2015;8(7).

33. Ranjbar R, et al. Genetic relatedness among isolates of Shigella sonnei carrying class 2 integrons in Tehran, Iran, 2002-2003. BMC Infect Dis. 2007;7(1):62.

34. Askarian Nameghi S. Genotyping Escherichia coli isolates by pulsed-field gel electrophoresis. Institutionen för livsvetenskaper. 2007.

35. Sabat A, et al. Overview of molecular typing methods for outbreak detection and epidemiological surveillance. Euro Surveill. 2013;18(4):20380.

36. Van Belkum A, et al. European Society of Clinical Microbiology and Infectious Diseases (ESCMID) Study Group on Epidemiological Markers (ESGEM). 2007. Guidelines for the validation and application of typing methods for use in bacterial epidemiology. Clin Microbiol Infect. 2007; 13(146):1469-0691.2007

37. Performance Standards for Antimicrobial Susceptibility Testing. 27th ed. CLSI supplement M100. Clinical and Laboratory Standards Institute, Wayne, PA, USA, 2017.

38. Ribot EM, et al. Standardization of pulsed-field gel electrophoresis protocols for the subtyping of Escherichia coli 0157: H7, Salmonella, and Shigella for PulseNet. Foodbourne Pathogens \& Disease. 2006;3(1):59-67.

39. Control, Cf.D and Prevention, Standard operating procedure for PulseNet PFGE of Escherichia coli O157: H7, Escherichia coli non-O157 (STEC), 
Salmonella serotypes, Shigella sonnei and Shigella flexneri. Centers for Disease Control and Prevention, Atlanta, 2013.

40. Cao X, et al. Genotypic characteristics of multidrug-resistant Escherichia coli isolates associated with urinary tract infections. APMIS. 2014;122(11): 1088-95.

41. Dong H-J, et al. Prevalence, virulence potential, and pulsed-field gel electrophoresis profiling of Shiga toxin-producing Escherichia coli strains from cattle. Gut pathogens. 2017;9(1):22.

42. Ejrnæs K. Bacterial characteristics of importance for recurrent urinary tract infections caused by Escherichia coli. Dan Med Bull. 2011;58(4):B4187.

43. Niranjan V, Malini A. Antimicrobial resistance pattern in Escherichia coli causing urinary tract infection among inpatients. Indian J Med Res. 2014;139(6):945.

44. Adib $\mathrm{N}$, et al. Antibiotic resistance profile and virulence genes of uropathogenic Escherichia coli isolates in relation to phylogeny. Trop Biomed. 2014;31(1):17-25.

45. Shakya $\mathrm{P}$, et al. Antibiotic resistance among Escherichia coli isolates from stool samples of children aged 3 to 14 years from Ujjain, India. BMC Infect Dis. 2013;13(1):477.

46. Villar $\mathrm{HE}$, et al. Frequency and antibiotic susceptibility patterns of urinary pathogens in male outpatients in Argentina. The Journal of Infection in Developing Countries. 2014;8(06):699-704

47. Jakovljević $\mathrm{E}$, et al. A one-year prospective study on the antibiotic resistance of $E$. coli strains isolated in urinary specimens of children hospitalized at the university pediatric medical Center in Novi sad, Serbia. Infection. 2013;41(6): $1111-9$.

48. Melo DB, et al. Antimicrobial resistance and genetic diversity of Escherichia coli isolated from humans and foods. Braz J Microbiol. 2015;46(4):1165-70.

49. Tarchouna M, et al. Distribution of uropathogenic virulence genes in Escherichia coli isolated from patients with urinary tract infection. Int I Infect Dis. 2013;17(6):e450-3.

50. Jalali HR, et al. Genotyping of virulence factors of Uropathogenic Escherichia coli by PCR. Novelty in Biomedicine. 2015;3(4):177-81.

51. Wiles TJ, Kulesus RR, Mulvey MA. Origins and virulence mechanisms of uropathogenic Escherichia coli. Exp Mol Pathol. 2008:85(1):11-9.

52. Usein CR, et al. Prevalence of virulence genes in Escherichia coli strains isolated from Romanian adult urinary tract infection cases. J Cell Mol Med. 2001;5(3):303-10

53. Akpaka PE, Jayaratne P. Usefulness of pulsed field gel electrophoresis assay in the molecular epidemiological study of extended spectrum beta lactamase producers. Gel electrophoresis-advanced techniques. 2012:193-202.

54. Watabe $\mathrm{M}$, et al. Epidemiological study of E. coli $\mathrm{O} 157$ : $\mathrm{H7}$ isolated in Northern Ireland using pulsed-field gel electrophoresis (PFGE). The Ulster medical journal. 2008;77(3):168.

55. Maluta RP, et al. Frequencies of virulence genes and pulse field gel electrophoresis fingerprints in Escherichia coli isolates from canine pyometra. Vet J. 2014:202(2):393-5.

56. Basim E, Basim H. Pulsed-field gel electrophoresis (PFGE) technique and its use in molecular biology. Turk J Biol. 2001:25(4):405-18

57. Anvarinejad $\mathrm{M}$, et al. Genotypic analysis of $E$. coli strains isolated from patients with cystitis and pyelonephritis. Iranian Red Crescent Medical Journal. 2012;14(7):408

58. Yamamoto $\mathrm{S}$, et al. Detection of urovirulence factors in Escherichia coli by multiplex polymerase chain reaction. FEMS Immunol Med Microbiol. 1995;12(2):85-90

59. Jones TF, et al. Characteristics of clusters of Salmonella and Escherichia coli 0157 detected by pulsed-field gel electrophoresis that predict identification of outbreaks. Foodborne Pathog Dis. 2016:13(12):674-8.

60. Struve C, Krogfelt KA. In vivo detection of Escherichia coli type 1 fimbrial expression and phase variation during experimental urinary tract infection. Microbiology. 1999;145(10):2683-90.

\section{Ready to submit your research? Choose BMC and benefit from:}

- fast, convenient online submission

- thorough peer review by experienced researchers in your field

- rapid publication on acceptance

- support for research data, including large and complex data types

- gold Open Access which fosters wider collaboration and increased citations

- maximum visibility for your research: over $100 \mathrm{M}$ website views per year

At BMC, research is always in progress.

Learn more biomedcentral.com/submissions 